\title{
Correction to: Visually Guided Search Behavior During Walking in Insects with Different Habitat Utilization Strategies
}

\author{
Karl Kral $(\mathbb{D}$
}

Published online: 1 February 2020

C) Springer Science+Business Media, LLC, part of Springer Nature 2020

\section{Correction to: J Insect Behav (2019) 32:290-305 https://doi.org/10.1007/s10905-019- 09735-8}

The original version of this article unfortunately contains some mistakes in literature references.

\section{Original version:}

Page 295: Evans 2016, p. 299: Mashanova et al. 2009

Cleal K, Prete FR (1996) The predatory strike of free ranging praying mantises, Sphodromantis lineola (Burr.). II. Strikes in the horizontal plane. Brain Behav Evol 48:191-204.

Collett TS, Paterson CR (1991) Relative motion parallax and target localisation in the locust, Schistocerca gregaria. J Comp Physiol A 169:615-621.

Evans AR (2016) A study of the behaviour of the Australian field cricket T. commodus (Walker)

The online version of the original article can be found at https://doi.org/10.1007/s10905-019-09735-8

\section{K. Kral $(\bowtie)$}

Institute of Biology, University of Graz, Universitaetsplatz 2,

A-8010, Graz, Austria

e-mail:karlkral@aon.at
(Orthoptera: Gryllidae) in the field and in habitat simulations. Ethology 62:269-290.

Horridge A, Duelli P (1979) Anatomy of the regional differences in the eye of the mantis Ciulfina. J Exp Biol 80:165-190.

Macquart D, Beugnon G, Latil G (2008) Sensorimotor sequence learning in the ant Gigantiops destructor. Anim Behav 75: 1693-1701.

Mashanova A, Oliver TH, Jansen VA (2009) Evidence for intermittency and a truncated power law from highly resolved aphid movement data. J R Soc Interface 7:199-208.

\section{Corrected version:}

Page 295: Evans 1983, p. 299: Mashanova et al. 2010

Cleal KS, Prete FR (1996) The predatory strike of free ranging praying mantises, Sphodromantis lineola (Burmeister). II. Strikes in the horizontal plane. Brain Behav Evol 48:191-204.

Collett TS, Paterson CJ (1991) Relative motion parallax and target localisation in the locust, Schistocerca gregaria. J Comp Physiol A 169:615-621. 
Evans AR (1983) A study of the behaviour of the Australian field cricket Teleogryllus commodus (Walker) (Orthoptera: Gryllidae) in the field and in habitat simulations. Z Tierpsychol 62:269-290.

Horridge GA, Duelli P (1979) Anatomy of the regional differences in the eye of the mantis Ciulfina. J Exp Biol 80:165-190.
Macquart D, Latil G, Beugnon G (2008) Sensorimotor sequence learning in the ant Gigantiops destructor. Anim Behav 75: 1693-1701.

Mashanova A, Oliver TH, Jansen VAA (2010) Evidence for intermittency and a truncated power law from highly resolved aphid movement data. J R Soc Interface 7:199-208. 